\title{
Finite-State Predictive Current Control of a Standalone DFIG-Based Wind Power Generation Systems: Simulation and Experimental Analysis
}

\author{
Mohammed Saci Chabani $^{1}$ (D) M. T. Benchouia ${ }^{1} \cdot$ A. Golea $^{1} \cdot$ Mohamed Becherif $^{2}$
}

Received: 9 December 2020 / Revised: 21 May 2021 / Accepted: 2 June 2021 / Published online: 15 July 2021

(c) Brazilian Society for Automatics--SBA 2021

\begin{abstract}
This paper presents an improved stator voltage magnitude and frequency control for standalone doubly fed induction generators (DFIGs) based wind power generation systems (WPGSs). The proposed technique uses a simple finite-state predictive current control (FS-PCC). In this control method, the switching vector for the IGBT is selected to minimize the error between the reference value and the predicted value of the rotor current. Moreover, the discrete-time models of (DFIG) are needed to predict the future value of the rotor current for all possible voltage vectors generated by the rotor-side converter (RSC). Since the classic control methods in the literature use inner control loops and are based on pulse width modulation (PWM), this method does not require complex modulation stages and omits the current control loops, which reduces the control requirements. The main objective in a standalone DFIG system is to keep the stator voltage has constant in amplitude and frequency and equal to the reference value, regardless of the changes in rotor speed or load. The proposed control strategy was implemented through a $3 \mathrm{~kW}$ DFIG prototype platform-based dSPACE 1104 card. The simulation and experimental results show that the proposed FS-PCC offers excellent reference tracking with less total harmonic distortion (THD) in stator voltages and rotor currents.
\end{abstract}

Keywords Standalone DFIGs · WPGSs. FS-PCC · Field-oriented control (FOC) · Rotor-Side Converter RSC · dSPACE 1104 card.

\section{Introduction}

Owing to the diminution of fuel fossil reserves and increased concern about $\mathrm{CO} 2$ emissions, which can cause a critical climate change, the wind energy systems (WESs) have become attractive and developed rapidly over the last few decades as a clean renewable energy source (Barra et al., 2016; Kumar, 2016; Soued et al., 2017). Despite the impacts of Covid-19, the most exclusively published statistics energy has appeared that the total additions of wind energy capacity in 2020 are expected to reach $65 \mathrm{GW}$, which increased by $8 \%$ compared with 2019 (Jaladi et al., 2020; Sadorsky, 2021; Slimane et al., 2020).

Mohammed Saci Chabani

medsaci11@gmail.com

1 LGEB Laboratory, University of Biskra, BP 145, 07000 Biskra, Algeria

2 FCLAB Laboratory, Belfort University, 90010 Belfort Cedex, France
Most wind power generation systems (WPGSs) around the world are using the doubly fed induction generators (DFIGs) due to their additional benefits, for instance, wider power capture capability over a large range of wind speeds. Besides, compared to permanent magnet synchronous generators (PMSGs) which require high-power converters, the DFIGs are more economical because they utilized back-toback converters limited at $25 \%-30 \%$ of the DFIG size for supporting a rotor speed variation of \pm 30 percentage (Dida \& Benattous, 2015a, 2015b; Ouanjli et al., 2017).

The field-oriented control (FOC) is an extremely traditional control technique that can be used for DFIG-based systems. This method has been extensively utilized especially in industrial applications. The principle of this method is to transfer the rotor current into a dq rotational reference frame. The FOC technique is implemented through a conventional inner PI controller beside the pulse width modulation (PWM) which can apply the switching sequences to the voltage source converter (VSC). The advantages and disadvantages of this algorithm have been already discussed in many works (Abdeddaim \& Betka, 2013; Abdeddaim et al., 
2014; Amrane et al., 2016; Bekakra \& Ben Attous, 2014; Benamor et al., 2019; Bouchiba et al., 2017; Mensou et al., 2019, 2020; Soued, 2019). One of the advantages is that the FOC provides accurate current conservation, which is the major goal in control of electrical drives. However, since the PI controllers and the modulation stage are needed for hardware implementation, the complexity and the control system cost will increase.

In the last years, finite-state predictive control (FS-PC) has been successfully used for several applications such as power electronics and electrical drives (Behera \& Thakur, 2018; Chebaani et al., 2017; Rahima et al., , 2019; Vazquez et al., 2017). However, concerning the DFIG-based WECS systems, only an FS-PCC strategy has been described in Mesloub et al. (2016), where neither addressing the standalone operation mode nor the experimental implementation has been reported.

The major contribution of this article is to adopt the FS-PCC for the standalone DFIGs to overcome the abovementioned disadvantages and improve the control of standalone DFIGs, this control approach seems not been covered yet by the previously published literature in the field of standalone DFIG applications. The idea of FS-PCC is to manipulate the discrete model of DFIG to predict the rotor current by each possible state. The switching state that gives a minimal cost function value will directly select during the next sampling period. Consequently, neither PI current regulators nor pulse width modulators were needed, which is a vital advantage of the proposed FS-PCC when compared with previous control methods. The main challenge of this work is to improve stator voltage and frequency control at variable wind speeds and varying loads. Furthermore, simulation and experimental results are provided in this article. The attain results manifest that the suggested control strategy has perfect transient performance and steady-state response during various load or speed variations.

This article is structured as follows: In Section (II), topology of the system is presented. In Section III, modeling of DFIG and the RSC is presented. The FOC is explained for standalone DFIG is described in Section IV with (FSPCC). In Section V, simulation and experimental results are extended for various operating conditions. Finally, a conclusion is given in Section VI.

\section{Standalone DFIG System Topology}

Figure 1 shows the configuration of a standalone WPGS integrated DFIG. Two-level voltage source converters with back-to-back structures have been included between the stator and rotor in this topology, which is well recognized as the load side converter (LSC) and (RSC). This paper concerns only the RSC and the standalone DFIG.
3 Mathematical Models of DFIG and RSC

\subsection{DFIG Mathematical Model}

The mathematical equations of the DFIG in complex-domain can be defined by referring all the rotor and stator quantities of the DFIG to the stator-windings as (Abad et al., 2011; Chikha $\&$ Barra, 2016). The stator and rotor voltage equations of the DFIG are

$v_{s}=R_{s} . i_{s}+\frac{d}{d t} \psi_{s}+j \cdot \omega_{m} \cdot \psi_{s}$

$v_{r}=R_{r} \cdot i_{r}+\frac{d}{d t} \psi_{r}$

$\psi_{s}=L_{s} . i_{s}+L_{m} . i_{r}$

$\psi_{r}=L_{r} . i_{r}+L_{m} . i_{s}$

where $v_{s}, v_{r}, i_{s}$ and $i_{r}$ represent the voltage in stator and rotor, the currents in stator and rotor, respectively. Moreover, $\psi_{s}$, $\psi_{r}$ denote the stator and rotor flux vectors, respectively. $R_{s}$ and $R_{r}$ are the resistances per phase in stator and rotor, respectively. $L_{S}, L_{r}$ are the inductances per phase in stator and rotor, respectively. $L_{m}$ is the mutual inductance, respectively, and $L_{m}$ is the electrical speed.

The leakage factor of the DFIG can be defined as

$\sigma=1-\frac{L_{m}^{2}}{L_{s} \cdot L_{r}}$

The stator and rotor fluxes relationship can be achieved by the manipulation of $(3,4,5)$ as

$\psi_{s}=\frac{L_{s}}{L_{m}} \cdot\left(\psi_{r}-\sigma \cdot L_{r} \cdot i_{r}\right)$

\subsection{RSC Mathematical Model}

In this work, the RSC is a two-level (VSC) that has six IGBT power switches intended for applying the FS-PCC method. The structure of the RSC and all rotor voltage vectors is depicted in Fig. 2. The switching sequences $\mathrm{S}$ can be composed as the following equation:

$S=\frac{2}{3} \cdot\left(S_{a}+a \cdot S_{b}+a^{2} \cdot S_{c}\right)$

where $a=e^{-j 2 \pi / 3}, S_{i}=1$ means $S_{i}$ on, $\overline{S_{i}}$ means off, and $i=a, b, c$. All rotor voltage vector $v$ is linked to the switching state $S$ by

$v=v_{d c} . S$

where $v_{d c}$ is the dc-link input voltage that supplies the RSC. 


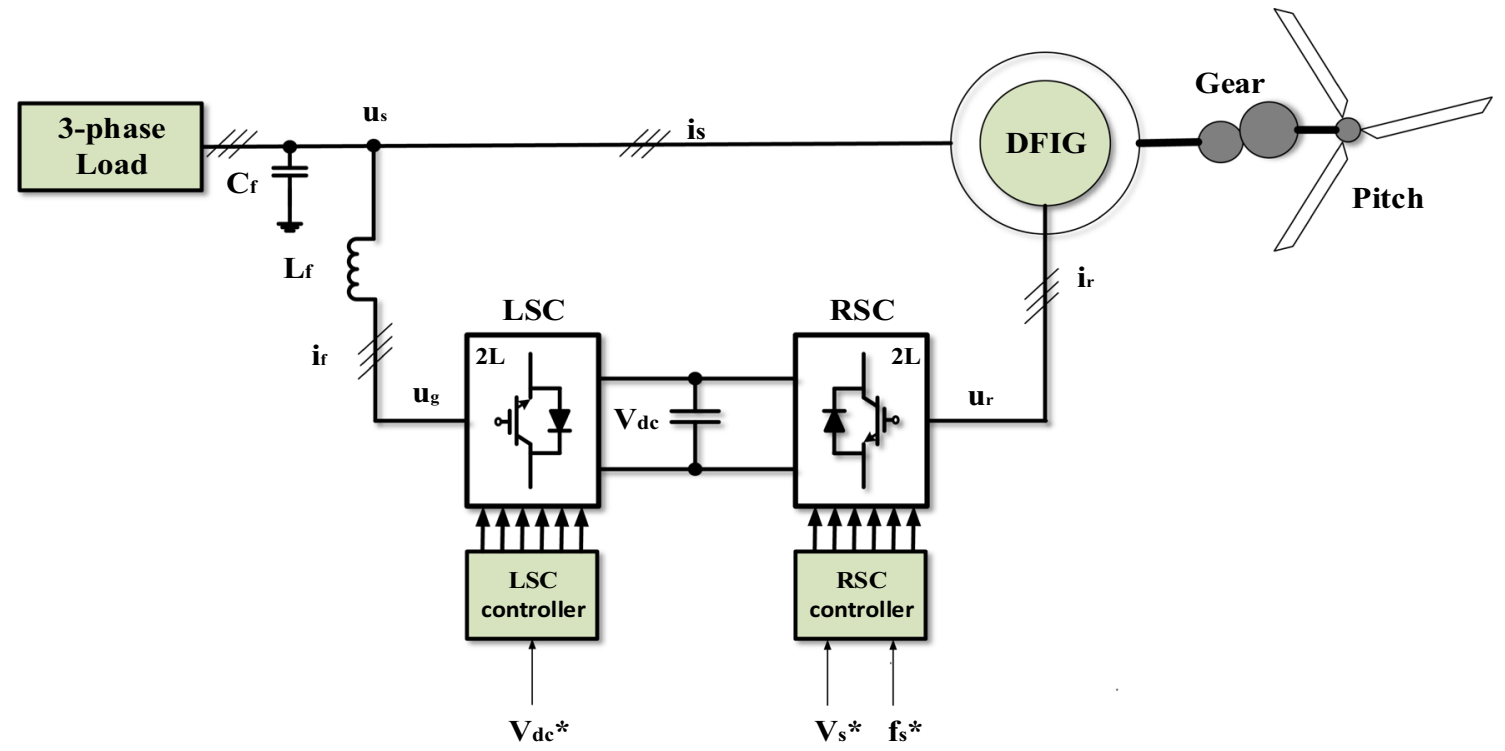

Fig. 1 Basic diagram of the standalone WPGSs
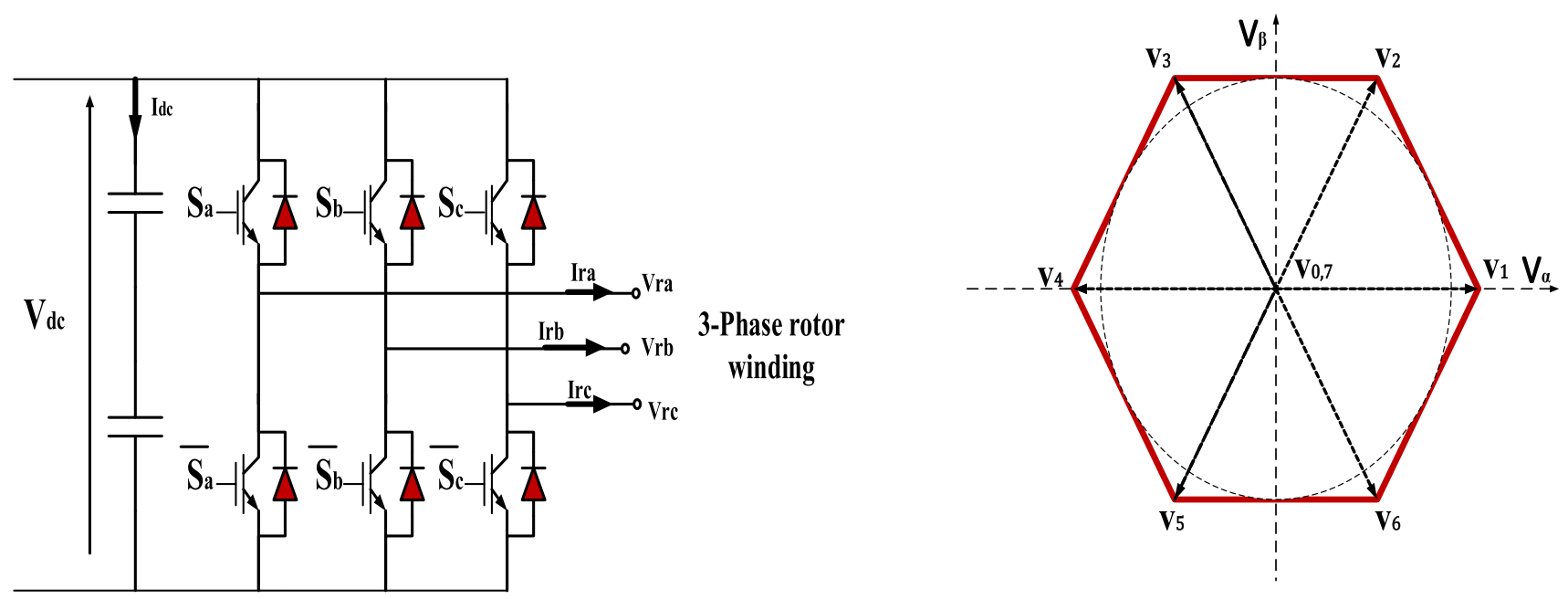

Fig. 2 Left: two-level voltage source inverter; right: voltage vectors

Considering the possible eight voltage $\mathrm{v}_{\mathrm{i}}\left(\mathrm{v}_{0}-\mathrm{v}_{7}\right)$ vectors switching states $\mathbf{S}\left(\mathrm{S}_{0}-\mathrm{S}_{7}\right)$ is obtained as shown in Table 1 .

The switching states of the RSC are controlled by the switching pulses $\mathrm{Sa}, \mathrm{Sb}, \mathrm{Sa}$ as follows:

$S_{a}=\left\{\begin{array}{l}1 \text { if } S_{\mathrm{a}} \text { on and } \overline{\mathrm{S}_{\mathrm{a}}} \text { off } \\ 0 \text { if } S_{\mathrm{a}} \text { off and } \overline{\mathrm{S}_{\mathrm{a}}} \text { on }\end{array}\right.$

$S_{b}=\left\{\begin{array}{l}1 \text { if } S_{\mathrm{b}} \text { on and } \overline{S_{\mathrm{b}}} \text { off } \\ 0 \text { if } S_{\mathrm{b}} \text { off and } \overline{S_{\mathrm{b}}} \text { on }\end{array}\right.$

$S_{C}=\left\{\begin{array}{l}1 \text { if } S_{\mathrm{c}} \text { on and } \overline{S_{\mathrm{c}}} \text { off } \\ 0 \text { if } S_{\mathrm{c}} \text { off and } \overline{S_{\mathrm{c}}} \text { on }\end{array}\right.$
Table 1 Voltage vectors and switching states with index number

\begin{tabular}{|c|c|c|c|c|}
\hline \multicolumn{3}{|c|}{ States Switching } & \multirow{2}{*}{$\frac{\text { Vectors Voltage }}{v_{i}=\left[\begin{array}{ll}v_{i \alpha} & v_{i \beta}\end{array}\right]}$} & \multirow{2}{*}{$\frac{\text { Vectors }}{\text { Number }}$} \\
\hline$S=\left[S_{a}\right.$ & $S_{b}$ & $\left.S_{c}\right]$ & & \\
\hline$S_{0}=[0$ & 0 & 0] & $v_{0}=[0,0] v_{1}=\left[2 V_{d c} / 3,0\right]$ & 0 \\
\hline$S_{1}=[1$ & 0 & 0] & $v_{2}=\left[V_{d c} / 3, \sqrt{3} V_{d c} / 3\right]$ & 1 \\
\hline$S_{2}=[1$ & 1 & 0] & $v_{3}=\left[-V_{d c} / 3, \sqrt{3} V_{d c} / 3\right]$ & 2 \\
\hline$S_{3}=[0$ & 1 & 0] & $v_{4}=\left[-2 V_{d c} / 3,0\right]$ & 3 \\
\hline$S_{4}=[0$ & 1 & 1] & $v_{5}=\left[-V_{d c} / 3,-\sqrt{3} V_{d c} / 3\right]$ & 4 \\
\hline$S_{5}=[0$ & 0 & 1] & $v_{6}=\left[\begin{array}{ll}V_{d c} / 3, & -\sqrt{3} V_{d c} / 3\end{array}\right]$ & 5 \\
\hline$S_{6}=[1$ & 0 & 1] & $v_{7}=[0,0]$ & 6 \\
\hline$S_{7}=[1$ & 1 & 1] & & 7 \\
\hline
\end{tabular}




\section{FOC for Standalone DFIG}

FOC is applied for the standalone DFIG to achieve the current decoupling control. The stator flux vector is oriented along the $d$-axis, while the stator voltage vector needs to align along the $q$-axis to achieve voltage-decoupling control (Chabani et al., 2017).

By forcing, the stator flux $\psi_{s q}$ and stator voltage $v_{s d}$ to be null the orientation are achieved. This leads to a dynamic first-order transfer function with a derivative-time equal to $\tau_{s}$ as below:

$\psi_{s d}=\left|\psi_{s}\right|=\frac{L_{m}}{\tau_{s} . s+1} . i_{r d}$

where stator time constant $\tau_{s}=\frac{L_{s}}{R_{s}}$, and

$\psi_{s q}=0=L_{s} \cdot i_{s q}+L_{m} \cdot i_{r q}$

That is

$i_{r q}=-\frac{L_{s}}{L_{m}} . i_{s q}$

\section{Proposed Finite-State Predictive Current Control for Standalone DFIG}

The rotor currents can be predicted for all sectors of the rotor voltage, in the proposed FS-PCC algorithm, these predicted rotor currents will contrast with the reference value of rotor current and then are evaluated by a simple cost function. The minimum value of the cost function will reveal the optimal vector rotor voltage which will be applied for the RSC in the next sampling period. (Behera \& Thakur, 2018; Chebaani et al., 2017; Mesloub et al., 2016).

\subsection{Rotor Current Prediction Model}

The prediction algorithm of the rotor current $i_{r}$ is based on the discrete Euler-forward model of the complex rotor current of the DFIG as

$\frac{d i_{r}}{d t} \approx \frac{i_{r}(k+1)-i_{r}(K)}{T_{S}}$

$T_{s}$ is the sampling time. Also, the rotor flux is estimated by:

$\psi_{r}(k)=\psi_{r}(k-1)+T_{s} .\left(v_{r}(k)-R_{r} . i_{r}(k)\right)$

Then, the stator flux can be estimated by using Eq. (6)
According to Barra et al., (2016); Soued et al., 2017), the rotor current is predicted through the expression as follows:

$$
\begin{aligned}
i_{r}(k+1)= & \left(1+\frac{T_{s}}{\tau_{\sigma}}\right) \cdot i_{r}(k)+\frac{T_{s}}{\tau_{\sigma}+T_{s}} . \\
& \times\left\{\frac{1}{R_{\sigma}}\left[\left(\frac{k_{s}}{\tau_{s}}+k_{s} j \omega_{m}\right) \psi_{s}(k)+v_{r}(k)-k_{s} v_{s}(k)\right]\right\}
\end{aligned}
$$

where $k_{s}=\frac{L_{m}}{L_{s}} \tau_{s}=\frac{L_{s}}{R_{s}} \tau_{\sigma}=\left(L_{r} * \sigma\right) / R_{\sigma} R_{\sigma}=R_{r}-R_{s} \cdot k_{s}^{2}$

In the actual systems that perform predictive control, a large amount of time calculation is required, and a large amount of retard time introduced during the excitation must be compensated. The time delay compensation of the FSPCC algorithm must be accomplished by advancing the current prediction two steps ahead (Chebaani et al., 2017; Vazquez et al., 2017). For instance, supposing that the determined vector will be used at the time $(\mathrm{k}+1)$, and then, it is necessary to predict the current value at $(\mathrm{k}+2)$ time. By moving (15) one time-step forward, the equation of ir $(\mathrm{k}+2)$ can be written as:

$$
\begin{aligned}
i_{r}(k+2)= & \left(1+\frac{T_{s}}{\tau_{\sigma}}\right) \cdot i_{r}(k+1)+\frac{T_{s}}{\tau_{\sigma}+T_{s}} . \\
& \times\left\{\frac{1}{R_{\sigma}}\left[\left(\frac{k_{s}}{\tau_{s}}+k_{s} j \omega_{m}\right) \psi_{s}(k+1)+v_{r}(k+1)-k_{s} v_{s}(k+1)\right]\right\}
\end{aligned}
$$

\subsection{Minimization of the Cost Function}

For the seven vectors of the rotor voltage which can be produced through the RSC, the rotor current will be predicted at the future sampling time. A cost function is made to evaluate all predicted rotor currents, and it is used as a condition for selecting the best vector of the rotor voltage. The vector of the rotor voltage that minimizes the cost value will choose to use in the next period. The cost function is expressed by the absolute error between the predicted and reference rotor current, as the below equation:

$g=\left|i_{r \alpha}^{*}(k)-i_{r \alpha}^{p}(k+2)\right|+\left|i_{r \beta}^{*}(k)-i_{r \beta}^{p}(k+2)\right|$

where $i_{r \alpha}^{*}(k)$ and $i_{r \beta}^{*}(k)$ are the reference of rotor currents in $\alpha \beta$ coordinate frame. Besides, $i_{r \alpha}^{p}(k+2)$ and $i_{r \beta}^{p}(k+2)$ are the predictive rotor currents.

\subsection{Proposed Controller Design}

Figure 3 shows the global control scheme of stator voltage and frequency control-based FS-PCC, and the output voltage magnitude in the stator of DFIG is controlled by regulating the d-rotor current $\left(i_{r d}\right)$. While the d-rotor current reference $\left(\mathrm{i}_{\mathrm{rd}}{ }^{*}\right)$ can be generated after reducing the error between the desired and measured voltage magnitude $\left(v_{a n}{ }^{*}\right.$ and $\left.v_{a n}\right)$ through a PI (Proportional Integral) controller (Kanojiya, 2012). The stator of the DFIG is connected in Y-mode; the 


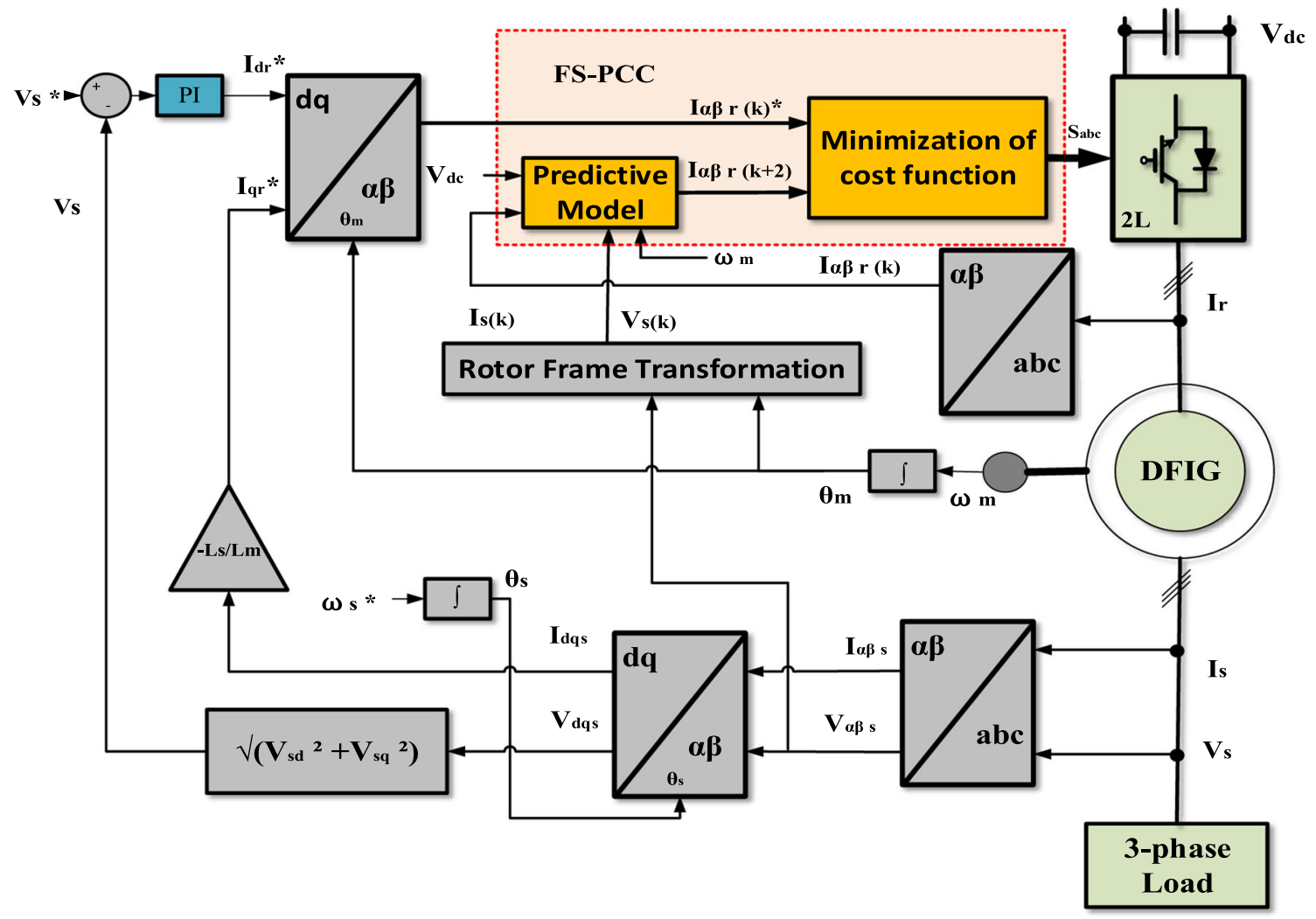

Fig. 3 Block diagram of FS-PCC of RSC

stator voltage magnitude ( $\left.v_{s}\right)$ is given by Ahmed et al. (2019) wind energy conversion system.

$\left|v_{s}\right|=V=\sqrt{\left(v_{s d}^{2}+v_{s q}^{2}\right)}$

For the standalone DFIG, the system produces electric power as much as the load demand. So, the reference of qrotor current $\left(i_{r q}\right)$ is calculated from the q-stator current $\left(i_{s q}\right)$ as (Abdeddaim \& Betka, 2013):

$i_{r q}^{*}=-\frac{L_{s}}{L_{m}} i_{s q}^{*}$

This proposed FS-PCC is developed to be realized in a fixed $\alpha \beta$ rotor reference frame. The Park transformation matrix and the reference rotor currents in $d q$ are transformed to $\alpha \beta$ coordinates by:

$\left[\begin{array}{c}i_{r \alpha}^{*} \\ i_{r \beta}^{*}\end{array}\right]=\left[\begin{array}{cc}\cos (\theta) & a m p ;-\sin (\theta) \\ \sin (\theta) & a m p ; \cos (\theta)\end{array}\right] \cdot\left[\begin{array}{c}i_{r d}^{*} \\ i_{r q}^{*}\end{array}\right]$

Finally, to control the output stator frequency at the desired value $\mathrm{fs}=50 \mathrm{~Hz}$, all the stator quantities must be synchronized with the dq rotating reference frame. Hene, the d-and q-axis of both stator voltages and stator currents are generated by transforming the three-phase stator quantities through the
Park transformation with angle $\left(\theta_{s}\right)$, which is obtained by integrating the reference stator frequency $\omega_{s}(314 \mathrm{rad} / \mathrm{sec})$ (Benamor et al., 2019) where

$\theta_{r}=\theta_{s}-\theta_{m}$

\section{Simulation Results and Experimental Validation}

This section presents simulation and experimental examination test results to verify the behavior of the developed FS-PCC. The simulation model has been built in MATLAB/Simulink together with the Sim Power Systems software. Moreover, the experimental results have been obtained using a test platform developed in the laboratory. The characteristics of the DFIG that used for simulation and experimental are reported in Appendix (A). Figure 4 portrays the descriptive diagram and a picture of the experimental prototype setup, and it is composed of a prime mover $3 \mathrm{Kw}$ DC motor, $3 \mathrm{Kw}$ DFIG, $4 \mathrm{Kw} / 420 \Omega$ three-phase resistive load. Semikron module IGBT inverter, dSPACE 1104 control card, a host PC running with MATLAB/Simulink software. The hardware DS1004 card is exploited to implement the FSPCC strategy, with a sampling time of $100 \mu \mathrm{s}$. 

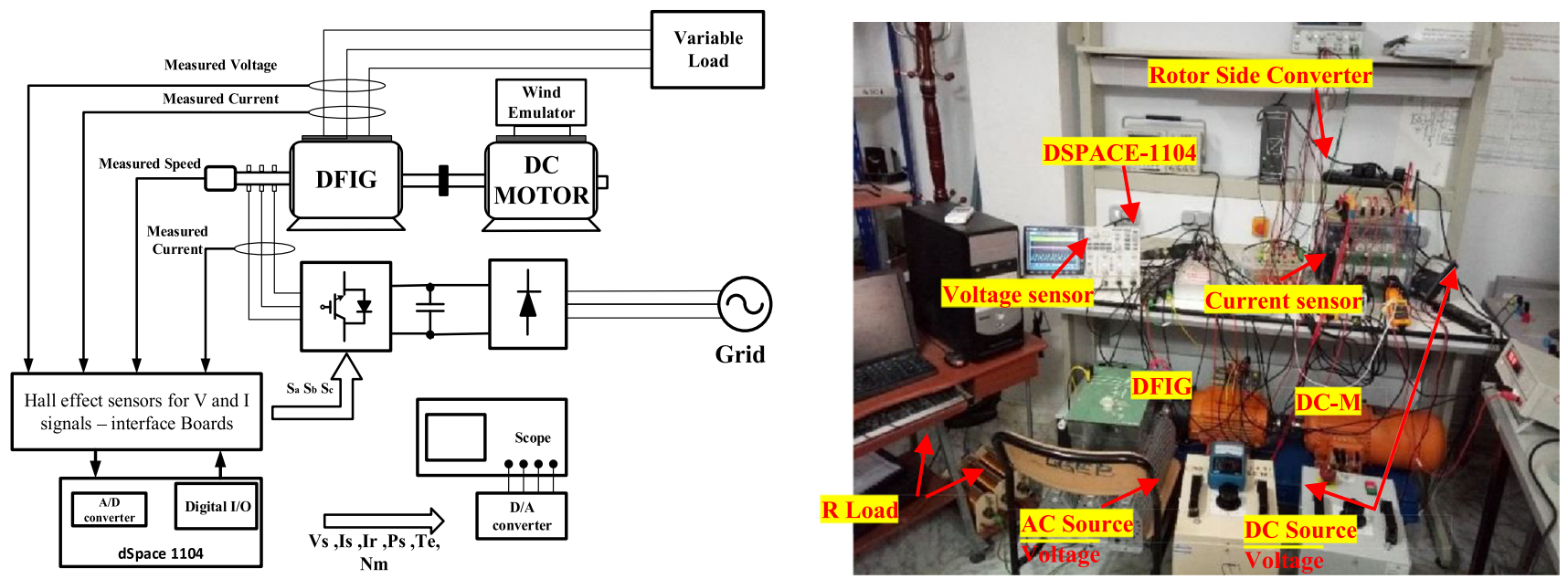

Fig. 4 A laboratory prototype of the experimental setup

(a)
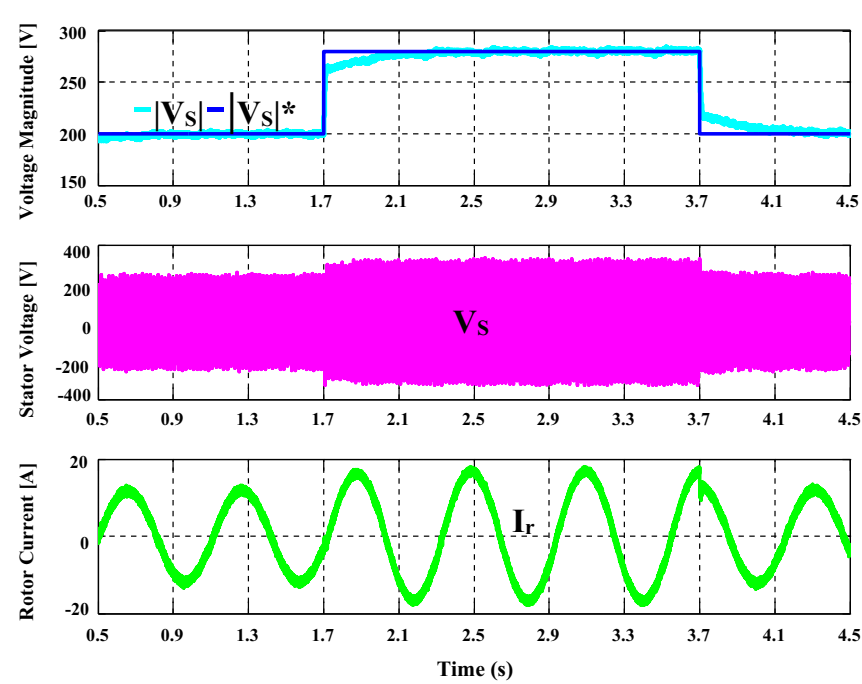

(b)

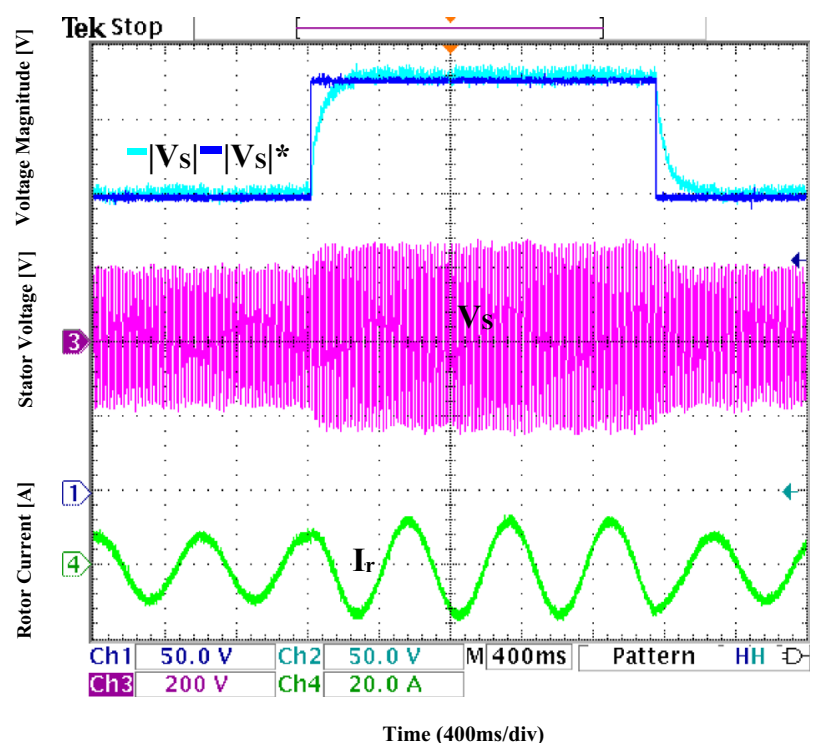

Fig. 5 System response under step variation in the reference of stator voltage amplitude.a Simulation results.b Experimental. CH1: reference of stator voltage magnitude (50 V/div), $\mathrm{CH} 2$ : stator voltage magnitude (50 V/div), $\mathrm{CH} 3$ : stator phase voltage (200 V/div), CH4: rotor phase current (20A/div)

To determine the performance of the proposed control method, the behavior of the controlled system is evaluated during the blow running conditions:

\subsection{Stator Voltage Magnitude Variation}

Firstly, the DFIG is driven with a constant speed of $1450 \mathrm{rpm}$ and supplies a fixed $2 \mathrm{Kw}$ of resistive load. To show the dynamic performance of the suggested technique, a variation in the reference of output voltage has been applied. The reference of the stator voltage amplitude has been varied from 200 to $280 \mathrm{~V}$ at $1.7 \mathrm{~s}$ from 280 to 200 at $3.7 \mathrm{~s}$. The vari- ous simulation and the experimental test results are shown in Figs. 5-6. Figure 6 (a), (b) illustrates the reference and actual stator voltage amplitude stator phase voltage and rotor phase current. It is easily seen that the stator voltage amplitude has a perfect reference tracking capability for any change in reference value. Both simulation and the experimental show that the stator voltage and the rotor current have good sinusoid waveform due to the application of FS-PCC. The transient behaviors of the applied FS-PCC method for rotor current in the $\alpha \beta$ axis are studied. Figure $5 \mathrm{a}, \mathrm{b}$ presents the reference and measured rotor currents in the $\alpha \beta$ axis in the presence of stator voltage steps, It can be noticed that the rotor cur- 
(a)
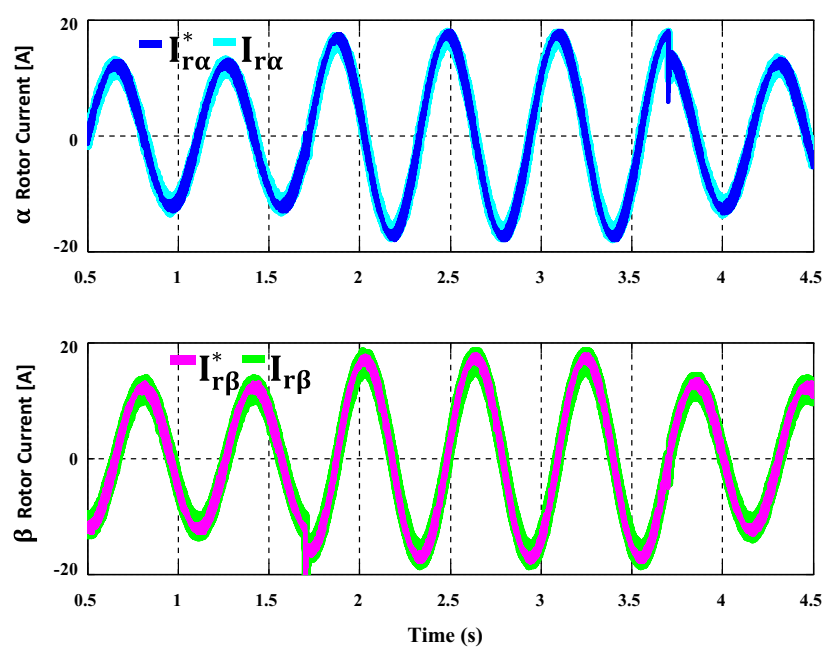

(b)

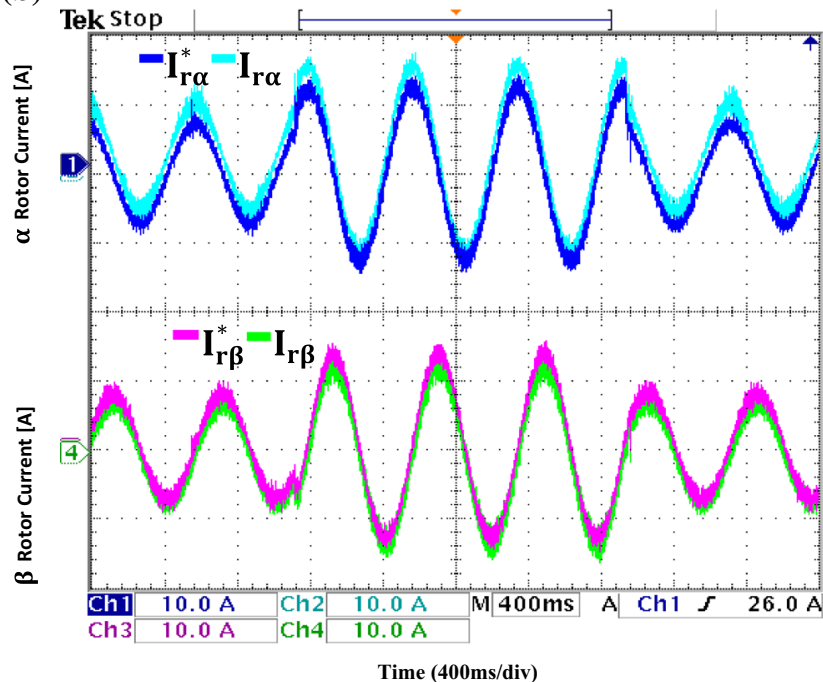

Fig. 6 Rotor currents response in $\alpha \beta$ under stator voltage change. a Simulation results. b Experimental. CH1: reference and measure rotor current in $\alpha$ axis (10A/div), $\mathrm{CH} 2$ : reference and measure rotor current in $\beta$ axis (10A/div)

(a)
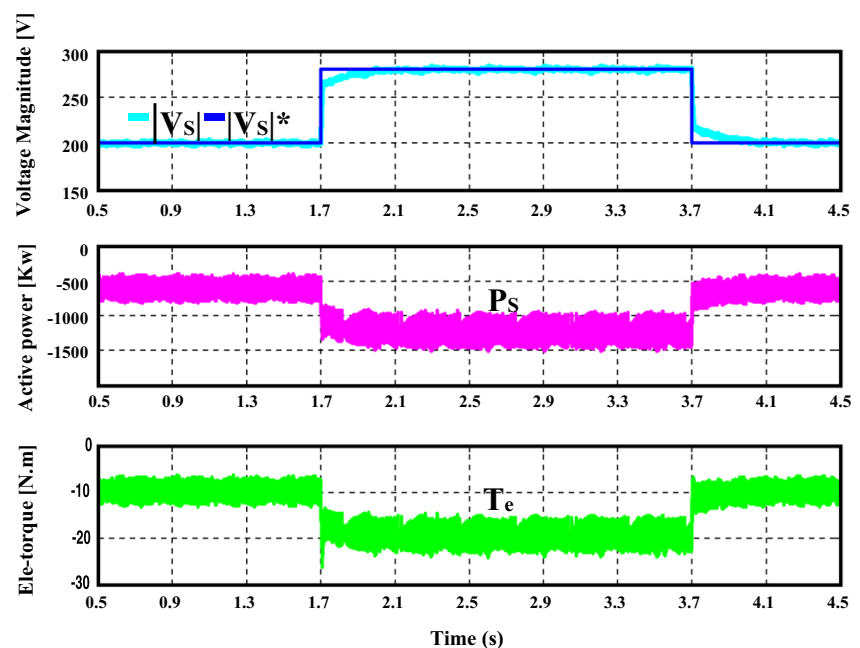

(b)

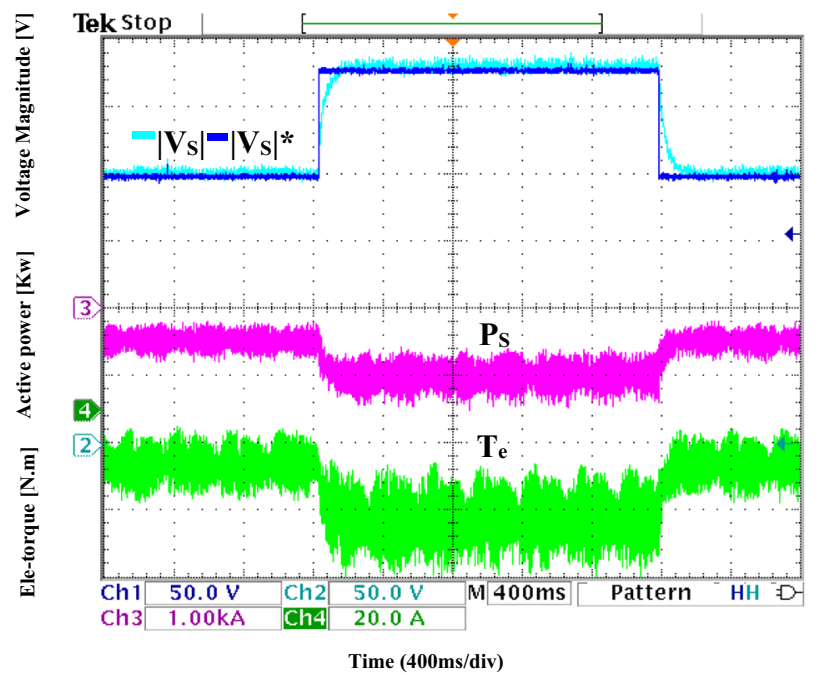

Fig. 7 System response under load variety.a Simulation results.b Experimental. CH1: reference of stator voltage magnitude (50 V/div), CH2: stator voltage magnitude (50 V/div), $\mathrm{CH} 3$ : stator phase current (5A/div), $\mathrm{CH} 4$ : rotor phase current $(20 \mathrm{~A} / \mathrm{div})$

rents are controlled successfully by the proposed FS-PCC method, which achieved a perfect transient response during step change of the stator voltage. Also, Fig. 6a, b shows the variation of stator active power and electromagnetic torque of the generator with low ripples when the stator voltage amplitude is varied by increasing and decreasing its value.

\subsection{Load Change}

To investigate the impact of the load change, which is connected to the stator of DFIG, the load is increased from 2 to $4 \mathrm{~kW}$ at $1.7 \mathrm{~s}$ and is decreased from 4 to $2 \mathrm{~kW}$ at $3.7 \mathrm{~s}$ when the DFIG operates with a constant rotor speed of 1450 $\mathrm{r} / \mathrm{min}$. The various simulation results and experimental tests are obtained with the proposed FS-PCC strategy under the variation in load value are shown in Figs. 7-8. Figure 7 a and $b$ illustrates the reference and measured stator voltage amplitude, stator current, and rotor current. It is obvious that stator voltage amplitude has been affected by load application, by showing an undershoot, then the amplitude has been recovered quickly because of the regulation loop. Also, the increase and decrease in the stator and rotor current are due 
(a)
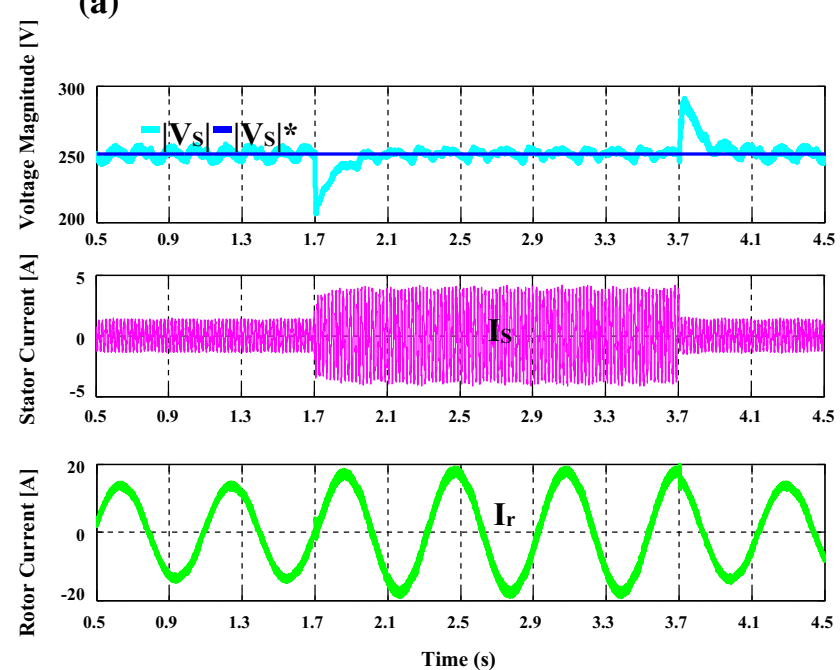

(b)

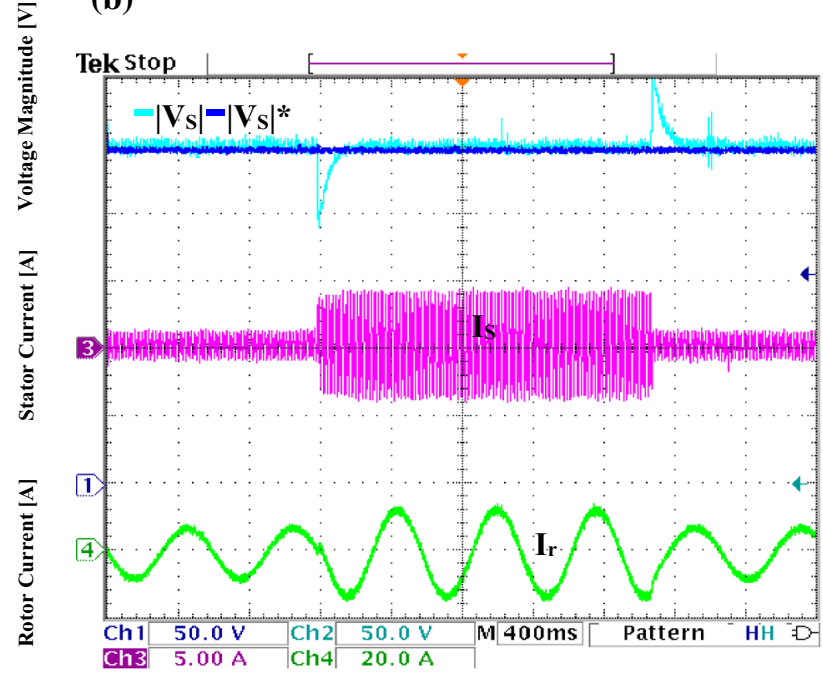

Time (400ms/div)

Fig. 8 System response under step variation in the reference of stator voltage amplitude. a Simulation results. b Experimental. CH1: reference of stator voltage magnitude $(50 \mathrm{~V} / \mathrm{div}), \mathrm{CH} 2$ : stator voltage magnitude $(50 \mathrm{~V} / \mathrm{div}), \mathrm{CH} 3$ : stator active power $(1 \mathrm{KW} / \mathrm{div})$, $\mathrm{CH} 4$ : electromagnetic torque $(20$ N.m/div)

(a)
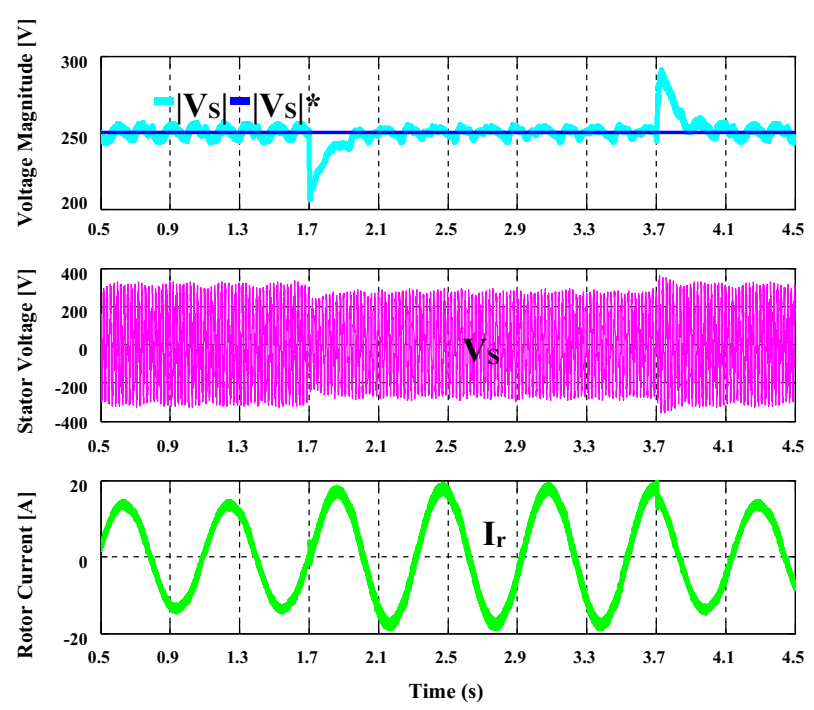

(b)

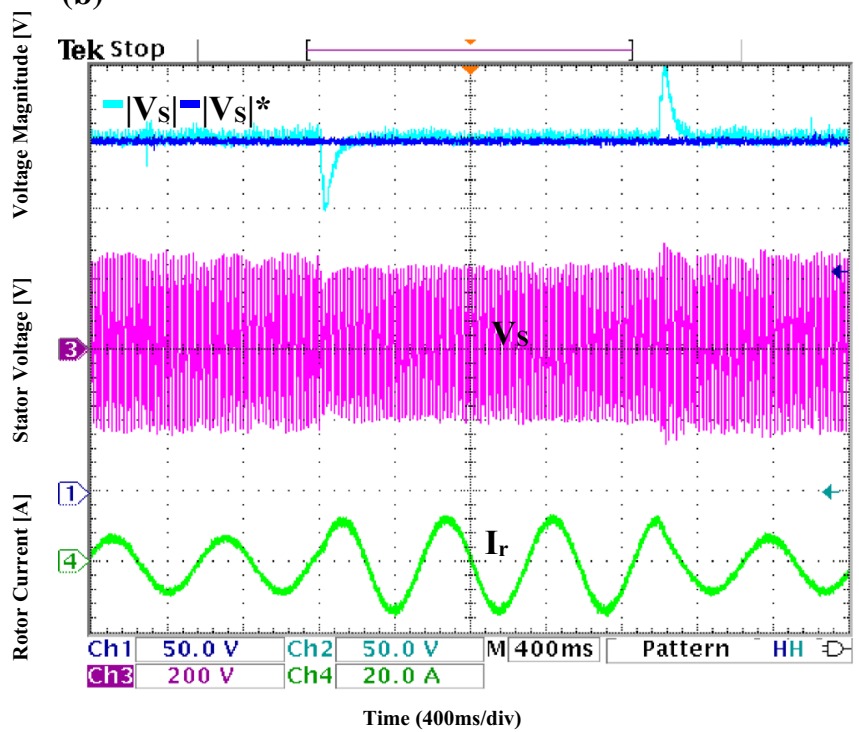

Fig. 9 System response under load variety. a Simulation results. b Experimental. CH1: reference of stator voltage magnitude (50 V/div), CH2: stator voltage amplitude (50 V/div), CH3: stator phase voltage (200 V/div), CH4: rotor phase current (20A/div)

to the increase and decrease in load value. Figure $9 a$ and $b$ shows that the stator voltage remains fixed at the desired value of $250 \mathrm{~V}$ despite the load variations. Figure $8 \mathrm{a}$ and $\mathrm{b}$ shows that the variation of stator active power and electromagnetic generator torque is evident due to the load variation. The negative value indicates that the delivered quantity is toward the load.

\subsection{Rotational Speed Variation}

To reveal the stability of the suggested FS-PCC strategy, the responses of the system are analyzed during emulating, and a different wind gust scenario has been considered. The speed of the DFIG is suddenly decreased from 1450 to $1300 \mathrm{rpm}$ at $1.7 \mathrm{~s}$ and increased from 1300 to $1450 \mathrm{rpm}$ at $3.7 \mathrm{~s}$. This test has been done with a fixed load of $2 \mathrm{~kW}$ and stator voltage $250 \mathrm{~V}$. The obtained results during this rotor speed 
(a)
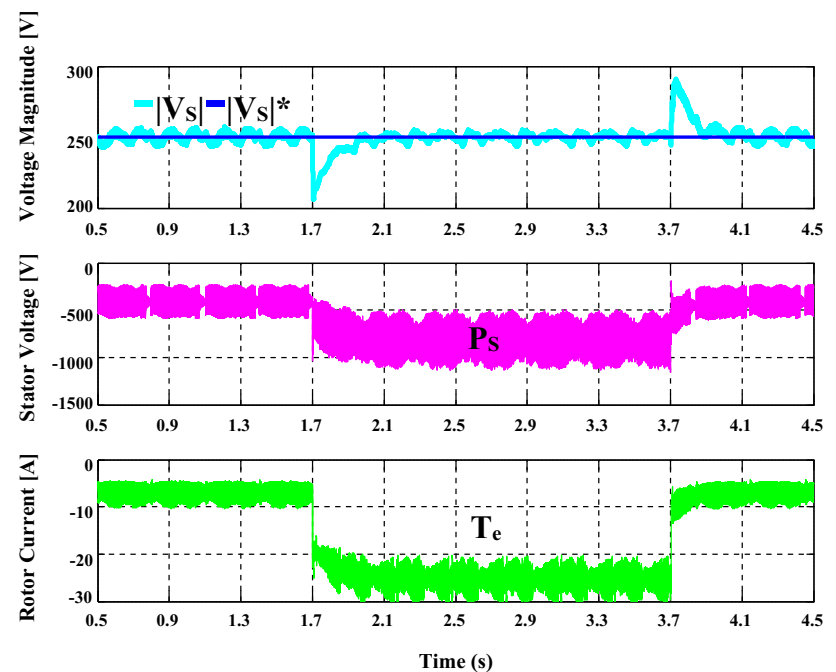

(b)

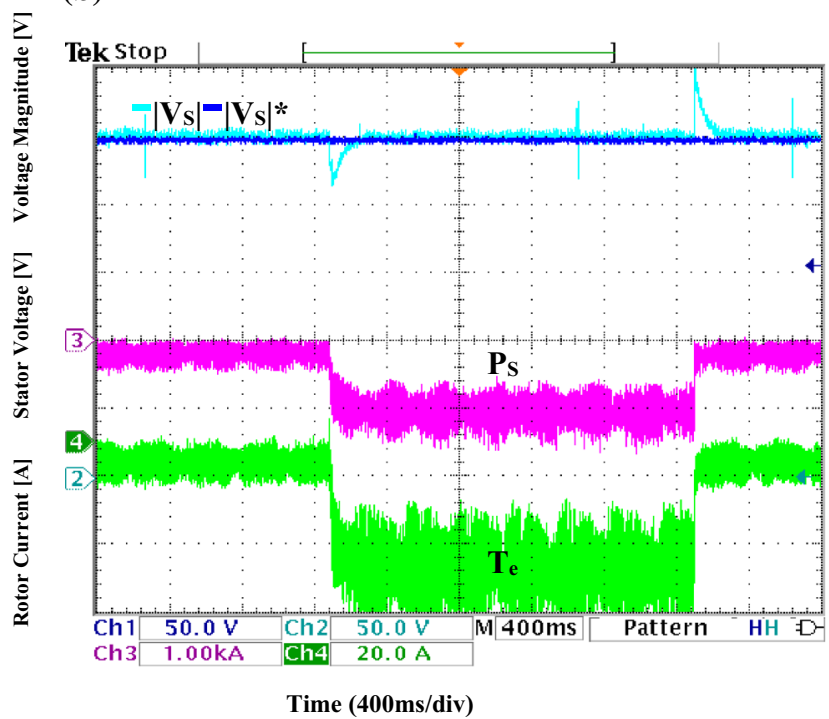

Fig.10 System response under load variety. a Simulation results. b Experimental. CH1: reference of stator voltage magnitude (50 V/div), CH2: stator voltage amplitude (50 V/div), CH3: stator active power (1KW/div), CH4: electromagnetic torque (20 N.m/div)

(a)
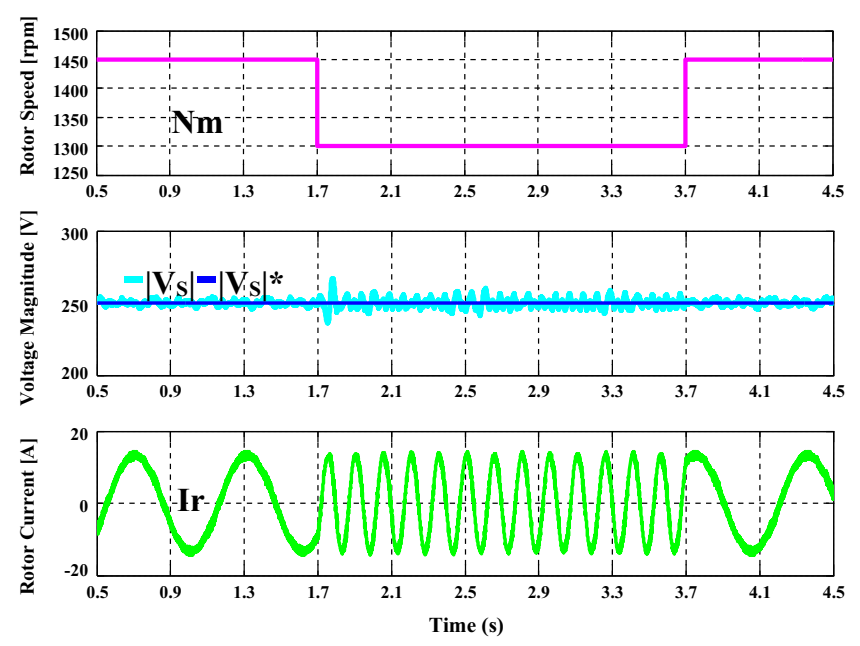

(b)

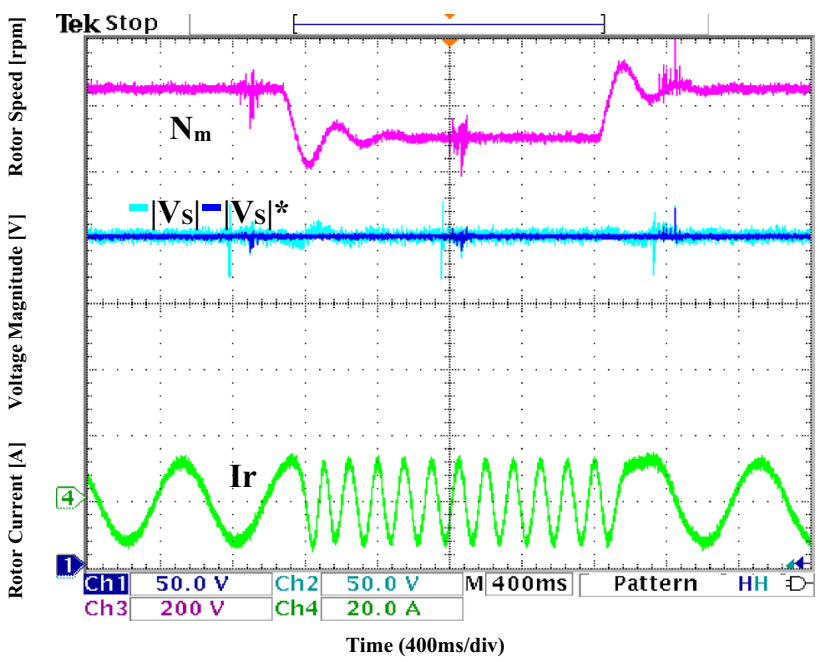

Fig. 11 System response under rotor speed variety. a Simulation results. b Experimental. CH1: rotor speed (200 rpm/div), CH2: reference of stator voltage amplitude (50 V/div), CH3: stator voltage magnitude (50 V/div), CH4: rotor phase current (20A/div)

change are shown in Figs. 10-11. Figure 10a and b illustrates the rotational speed, the reference, and actual stator voltage amplitudes, the rotor current. It can be seen that the magnitude is not affected at all and tracks the reference perfectly for the entire period of test, Fig. 11a and b illustrates the rotational speed, the slip angle, stator voltage, and rotor current, it is also seen that the variation of the frequency of rotor current is evident due to the rotor mechanical speed variation. Thus, from zoom (1) and (2), it is observed that the stator voltage frequency remains constant at $50 \mathrm{~Hz}$ despite the variation in rotor speed due to the sum of the mechanical and electrical rotor current frequency (Fig. 12).

\subsection{THD Assessment}

The other important issue in standalone DFIG mode is the power quality since the loads are mostly need balanced and non-polluted stator voltage. Therefore, to evaluate the proposed controller scheme, the power quality of the standalone DFIG system is investigated. The THD of the rotor $I_{r a}$ current and stator voltage $V_{s a}$ is obtained at rotor speed $1450 \mathrm{rpm}$. In Fig. 13a and b, the THD of $I_{r a}$ is $3.41 \%$ for fundamental rotor frequency: $f_{r}=1.667 \mathrm{~Hz}$ and THD in the stator voltage windings for fundamental rotor frequency $50 \mathrm{~Hz}$ is and $4.24 \%$. 
(a)
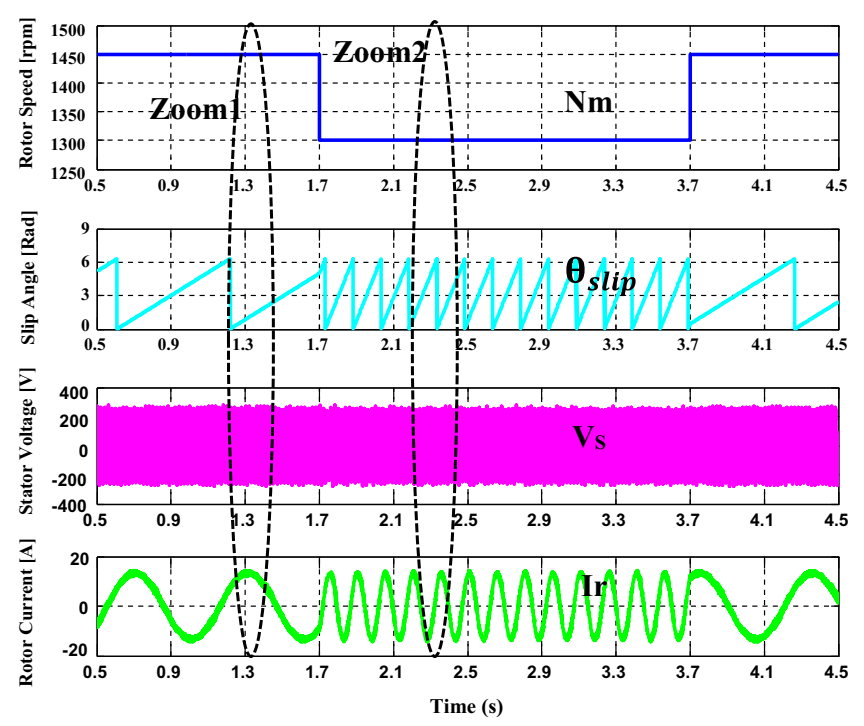

(b)

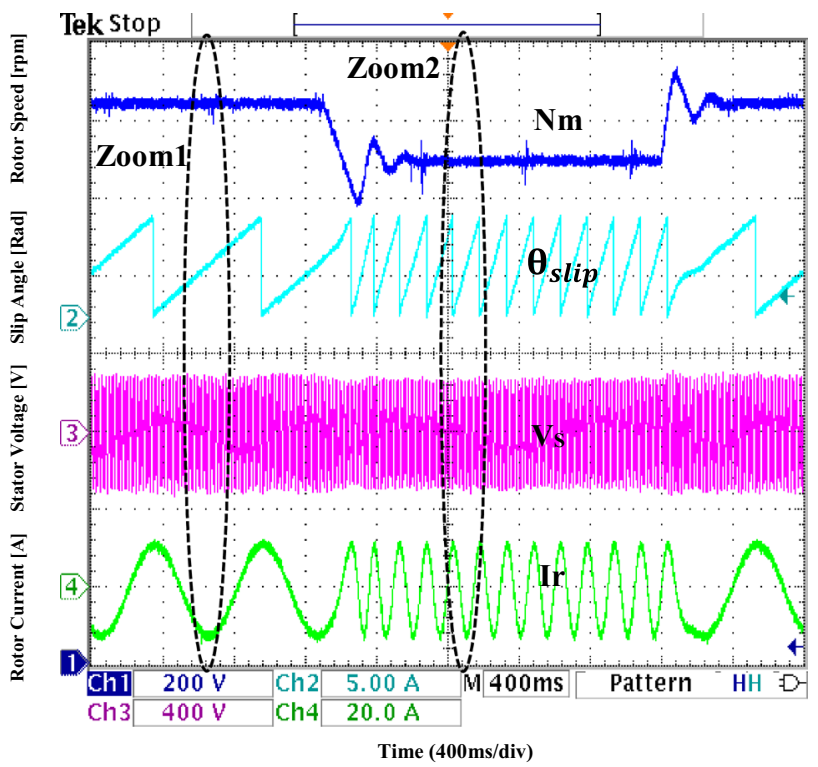

Fig. 12 System response under rotor speed variety. a Simulation results. b Experimental. CH1: rotor speed (200 rpm/div), CH2: slip angle (5 rad/div), $\mathrm{CH} 3$ : stator phase voltage (400 V/div), $\mathrm{CH} 4$ : rotor phase current (20A/div)

(a)
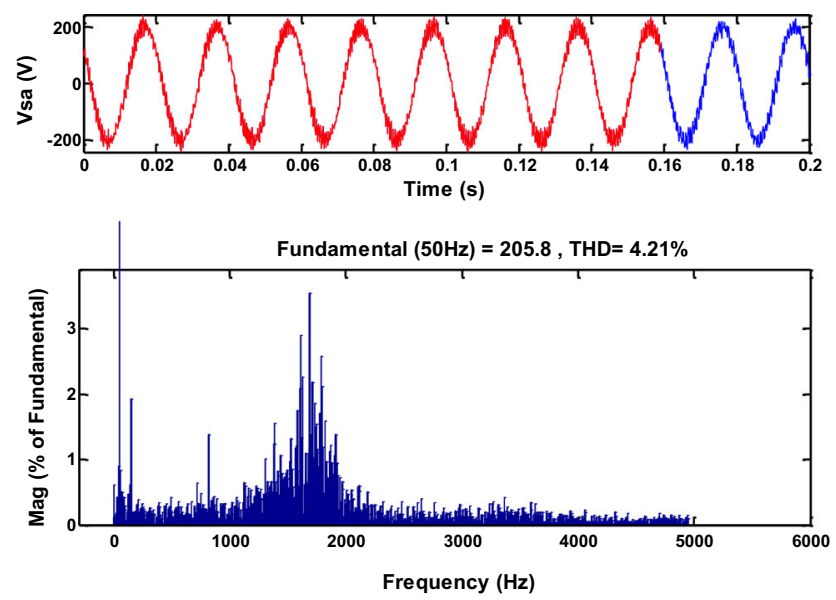

(b)
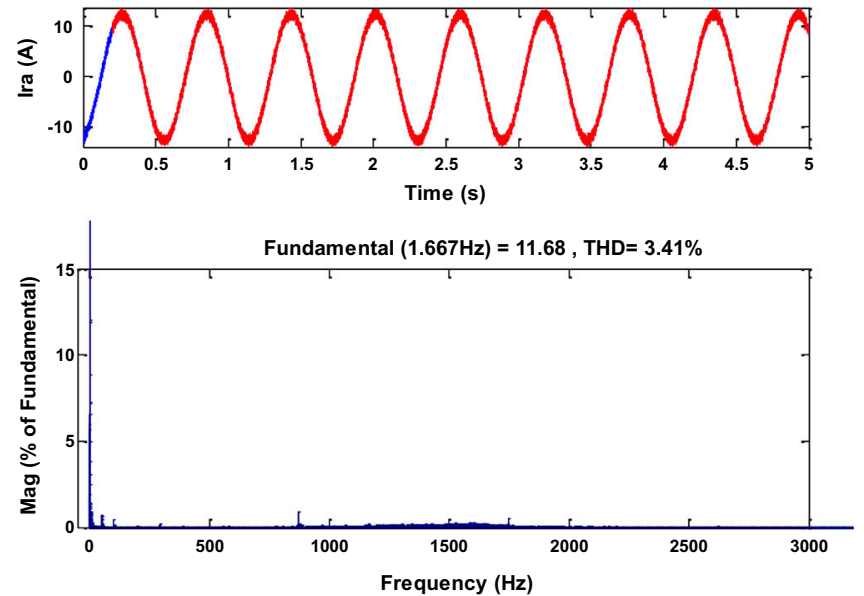

Fig. 13 Experimental THD analysis. a Phase stator voltage THD. b Phase rotor current THD

\section{Conclusion}

In this paper, a simple and effective FS-PCC algorithm for the stator voltage and frequency control for a standalone DFIG has been developed. The proposed controller does not require an inner PI controller or a complex modulation stage, which greatly simplifies the design process. Moreover, it is easy to implement in the $\alpha \beta$ synchronizes rotor reference frame, thereby keeping the proposed control algorithm straightforward for the handling of constraints. Simulation results and experimental tests in a laboratory with a $3 \mathrm{~kW}$ DFIG scale setup confirm the proposed control algorithm and show the feasibility and effectiveness of the proposed FS-PCC concerning different operating conditions.

\section{Appendix 1}

See Tables 2 and 3. 
Table 2 DFIG main parameters

\begin{tabular}{lll}
\hline Parameters & Value & Unit \\
\hline Nominal power & 3 & $\mathrm{~kW}$ \\
Stator voltage & 325.26 & $\mathrm{~V}$ \\
Stator frequency & 50 & $\mathrm{~Hz}$ \\
Number of pairs poles & 2 & \\
Nominal speed & 1450 & $\mathrm{Rpm}$ \\
Stator resistance & 1.6000 & $\Omega$ \\
Rotor resistance & 2.6200 & $\Omega$ \\
Stator inductance & 0.1950 & $\mathrm{H}$ \\
Rotor inductance & 0.1950 & $\mathrm{H}$ \\
Mutual inductance & 0.1770 & $\mathrm{H}$ \\
\hline
\end{tabular}

Table 3 PI regulator parameters

\begin{tabular}{ll}
\hline $\mathbf{K}_{\mathbf{p}}$ & $\mathbf{K}_{\mathbf{i}}$ \\
\hline 0.07 & 3.4 \\
\hline
\end{tabular}

\section{References}

1. G. Abad, J. López, M. A. Rodríguez, L. Marroyo, and G. Iwanski, Doubly fed induction machine: Modeling and control for wind energy generation. 2011.

2. Abdeddaim, S., \& Betka, A. (2013). Optimal tracking and robust power control of the DFIG wind turbine. International Journal of Electrical Power \& Energy Systems, 49(1), 234-242.

3. Abdeddaim, S., Betka, A., Drid, S., \& Becherif, M. (2014). Implementation of MRAC controller of a DFIG based variable speed grid connected wind turbine. Energy Convers. Manag., 79, 281-288.

4. Ahmed, M., Metwaly, M. K., \& Elkalashy, N. (2019). Performance investigation of multi-level inverter for DFIG during grid autoreclosure operation. International Journal of Power Electronics and Drive Systems, 10(1), 454.

5. F. Amrane, A. Chaiba, B. E. Babes, and S. Mekhilef, "Design and implementation of high performance field oriented control for grid-connected doubly fed induction generator via hysteresis rotor current controller," Rev. Roum. des Sci. Tech. Ser. Electrotech. Energ., vol. 61, no. 4, pp. 319-324, 2016.

6. Barra, A., Ouadi, H., Giri, F., et al. (2016). Sensorless nonlinear control of wind energy systems with doubly fed induction generator. Journal of Control Automation and Electrical System, 27, 562-578. https://doi.org/10.1007/s40313-016-0263-1

7. Behera, R. R., \& Thakur, A. (2018). Finite-control-set predictive current control based real and reactive power control of grid-connected hybrid modular multilevel converter. International Journal of Power Electronics and Drive Systems, 9(2), 660-667.

8. Y. Bekakra and D. Ben Attous, "Optimal tuning of PI controller using PSO optimization for indirect power control for DFIG based wind turbine with MPPT,” Int. J. Syst. Assur. Eng. Manag., vol. 5, no. 3, pp. 219-229, 2014.

9. Benamor, A., Benchouia, M. T., Srairi, K., \& Benbouzid, M. E. H. (2019). A new rooted tree optimization algorithm for indirect power control of wind turbine based on a doubly-fed induction generator. ISA Transactions, 88, 296-306.

10. N. Bouchiba, A. Barkia, S. Sallem, L. Chrifi-Alaoui, S. Drid, and M. B. A. Kammoun, "Implementation and comparative study of control strategies for an isolated DFIG based WECS," Eur. Phys. J. Plus, vol. 132, no. 10, 2017.
11. Chebaani, M., Goléa, A., Benchouia, M. T., \& Goléa, N. (2017). Sliding mode predictive control of induction motor fed by five-leg AC-DC-AC converter with dc-link voltages offset compensation. Journal of Control Automatuion and Electrical System, 28(5), 597-611.

12. Chikha, S., \& Barra, K. (2016). Predictive control of variable speed wind energy conversion system with multi objective criterions. Periodica Polytechnica Electrical Engineering Computer Science, 60(2), 96-106.

13. Dida, A., \& Benattous, D. (2015a). Doubly-fed induction generator drive system based on maximum power curve searching using fuzzy logic controller. International Journal of Power Electronics and Drive Systems, 5(4), 583-594.

14. Dida, A., \& Benattous, D. (2015b). Modeling and control of DFIG through back-to-back five levels converters based on neuro-fuzzy controller. Journal of Control Automation and Electrical System, 26(5), 506-520.

15. El Ouanjli, N., Derouich, A., El Ghzizal, A., El Mourabit, Y., Bossoufi, B., \& Taoussi, M. (2017). Contribution to the performance improvement of doubly fed induction machine functioning in motor mode by the DTC control. International Journal of Power Electronics and Drive Systems, 8(3), 1117-1127.

16. Jaladi, K. K., Sandhu, K. S., \& Bommala, P. (2020). Real-Time simulator of DTC-FOC-based DFIG during voltage dip and LVRT. Journal of Control Automation and Electrical System, 31, 402-411.

17. Kanojiya, R. G. (2012). Method for speed control of DC motor. In International Conference On Advances In Engineering, Science And Management (pp. 117-122).

18. Kumar, Y., et al. (2016). Wind energy: Trends and enabling technologies. Renewable and Sustainable Energy Reviews, 53, 209-224.

19. S. Mensou, A. Essadki, I. Minka, T. Nasser, B. B. Idrissi, and L. Ben Tarla, "Performance of a vector control for dfig driven by wind turbine: Real time simulation using DS1104 controller board," Int. J. Power Electron. Drive Syst., vol. 10, no. 2, pp. 1003-1013, 2019.

20. S. Mensou, A. Essadki, T. Nasser, B. B. Idrissi, and L. Ben Tarla, "Dspace DS1104 implementation of a robust nonlinear controller applied for DFIG driven by wind turbine," Renew. Energy, vol. 147, pp. 1759-1771, 2020.

21. Mesloub, H., Benchouia, M. T., Goléa, A., Goléa, N., \& Benbouzid, M. E. H. (2016). Predictive DTC schemes with PI regulator and particle swarm optimization for PMSM drive: Comparative simulation and experimental study. International Journal of Advanced Manufacturing Technology, 86(9-12), 3123-3134.

22. B. Rahima, G. Amar, B. Mohamed Toufik, and C. Mohamed, "High performance active power filter implementation based on predictive current control," International Journal of Power Electronics and Drive Systems (IJPEDS),10(1), pp. 277,2019.

23. Chabani, M. S., Benchouia, M. T., Golea, A., \& Boumaaraf, R. (2017). Implementation of direct stator voltage control of standalone DFIG based wind energy conversion system. In 2017 5th International Conference on Electrical Engineering - Boumerdes (ICEE-B).

24. Sadorsky, P. (2021). Wind energy for sustainable development: Driving factors and future outlook. Journal of Cleaner Production, 289, 125779. https://doi.org/10.1016/j.jclepro.2020.125779

25. Slimane, W., Benchouia, M. T., Golea, A., \& Drid, S. (2020). Second order sliding mode maximum power point tracking of wind turbine systems based on double fed induction generator. International Journal of Systems Assurance Engineering and Management, 11(3), 716-727.

26. Soued, S., et al. (2019). Experimental behaviour analysis for optimally controlled standalone DFIG system. IET Electric Power Applications, 13(10), 1462-1473. 
27. Soued, S., Ebrahim, M. A., Ramadan, H. S., \& Becherif, M. (2017). Optimal blade pitch control for enhancing the dynamic performance of wind power plants via metaheuristic optimisers. IET Electric Power Applications, 11(8), 1432-1440.
28. Vazquez, S., Rodriguez, J., Rivera, M., Franquelo, L. G., \& Norambuena, M. (2017). Model predictive control for power converters and drives: Advances and trends. IEEE Transactions on Industrial Electronics, 64(2), 935-947.

Publisher's Note Springer Nature remains neutral with regard to jurisdictional claims in published maps and institutional affiliations. 